\section{Incidental Finding of Giant Aneurysm of Trunk of the Pulmonary Artery}

\section{Abstract}

Introduction: Pulmonary artery aneurysm (PAA) is a rare condition and associated with multiple pathologies. In most cases there are reports of dyspnea and palpitation, however, some patients are completely asymptomatic. Its natural history is uncertain and there are no clear guidelines about its treatment and monitoring.

Method: This is one case report, obtained through data from medical records of a reference hospital, located in the city of Juazeiro do Norte, Ceará, Brazil.

Case Report: Patient, female, 64 years old, healthy, sought medical assistance after a clinical picture of drug allergy. The physical examination performed at admission revealed hyperdynamic precordium associated with systolic thrills and murmur. Her chest radiography (X-ray) revealed a mediastinal widening, which after $\mathrm{CT}$ evaluation, it was found that it was a large aneurysm of trunk of the pulmonary artery. As it remained asymptomatic throughout the investigation and she refused to undergo surgical treatment, there was the adoption of a conservative conduct only with an outpatient treatment.
Thyciara Fontenele Marques ${ }^{1}$, Fernanda Moura Victor ${ }^{1}$, José Célio Couto Vasconcelos ${ }^{1}$, Ricardo Parente Garcia Vieira', Susyane Ribeiro Beserra1, Hermes Melo Teixeira Batista1,2, Samuel Soares Eduardo ${ }^{1}$, Antonia Rayanne Xavier Barbosa', Italla Maria Pinheiro Bezerra2 ${ }^{2}$ Luiz Carlos de Abreu $^{2}$

\section{Hospital regional do Cariri \\ 2 Laboratório de Delineamento de Estudos e Escrita Científica. Departamento de Saúde da Coletividade. Disciplina de Metodologia Científica.}

\section{Contact information:}

\section{Hermes Melo Teixeira Batista}

$\equiv$ hermesmelo@oi.com.br

\section{Keywords}

pulmonary artery, aneurysm.

\section{Introduction}

Pulmonary artery aneurysm (PAA), a pathological dilatation of the pulmonary artery and/or one of its main branches, is a rare condition whose prevalence is still unknown. Studies have reported one case for every 14,000 autopsies [1]. Although there is no precise definition for the PAA as occurs for the aortic aneurysm, some authors have indicated four centimeters in diameter as a cut-off point, although more recent studies involving computed tomography have reported a normal upper limit of the pulmonary artery diameter of $29 \mathrm{~mm}$ [2-4].

Several etiologies have been described in its pathogenesis from congenital heart defects, infections, vasculitis, connective tissue disease, tuberous 
sclerosis, traumas, arteriovenous fistulas, and even atherosclerosis disease. After introduction of the use of antibiotics, the PAA of noninfectious cause became the most common etiology [5-7]. However, when no pathological condition is identified and in the absence of structural or functional abnormalities of the cardiovascular system, the PAA is named as idiopathic [8].

It is clinically manifested by nonspecific symptoms such as chest pain, dyspnea, cough, hemoptysis or palpitations [9]. Some patients, however, are totally asymptomatic and the PAA is casually detected in imaging studies realized because of other reasons [10]. Depending on their size, they can lead to significant complications, including, in rare cases, airway compression. The rupture and/or dissection of the aneurysms in low-pressure chambers are of rare occurrence [11].

There are no clear guidelines about the treatment of the PAA and the patients can be treated individually. The treatment can be clinical, surgical or endovascular. Clinically, the control of the pulmonary pressure, predisposing factors and underlying disease is imperative [12]. Surgical treatment is usually indicated in the most unstable aneurysms with hemoptysis and in which a fatal outcome because of increased risk of rupture is foreseeable [13]. The endovascular therapy is reserved for when the clinical treatment alone fails to control the evolution of the disease, especially when the surgical repair entails high rates of morbidity and mortality $[13,14]$.

\section{Case Report}

Patient, female, 64 years old, without previous comorbidities, was admitted in a service of reference with diffuse pruritic rash and facial edema after the use of anti-emetic medication. She denied chest pain, cough, hemoptysis, palpitations, dyspnea or cyanosis and prior history of drug allergy. She was not using any other drugs, alcohol or cigarettes.
Figure 1: Chest radiography (X-ray) showing mediastinal widening with prominence of the middle arc corresponding to trunk of the pulmonary artery and the outer edge of the right atrium.

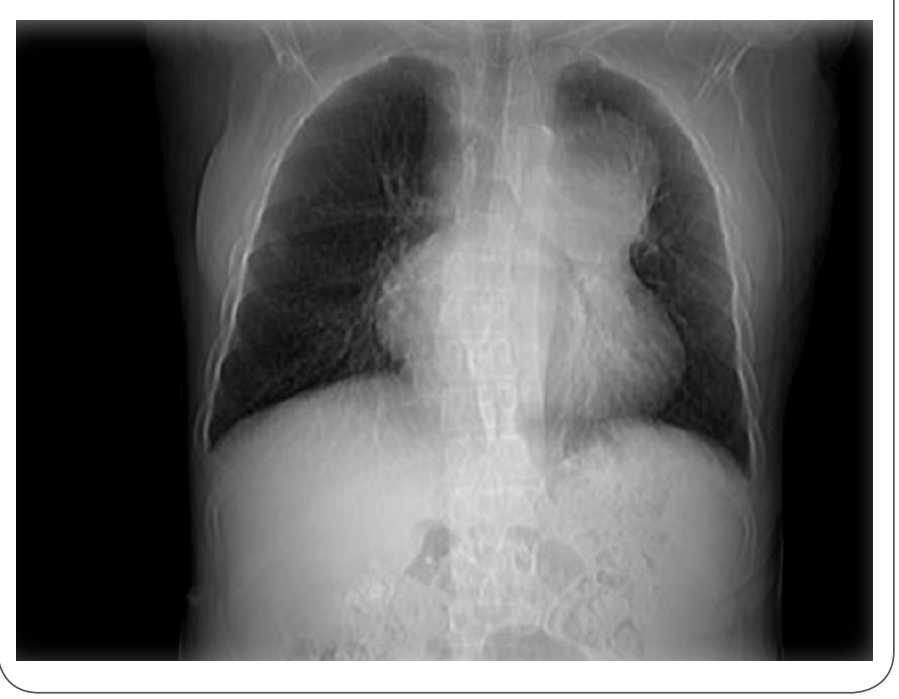

On examination, she was normotensive, with symmetric peripheral pulses and normal capillary refill. A hyperdynamic precordium with thrill to palpation was evidenced, severe systolic murmur best heard in pulmonary and tricuspid focus, and heart rate of 64 beats per minute. Her laboratory evaluation revealed no abnormalities with normal inflammatory tests, negative serology for schistosomiasis, nonreactive to ANF, HIV and VDRL. The chest radiography (Figure 1) revealed a mediastinal widening; the electrocardiogram suggested overload of the right chambers and the chest tomography (figures $\mathbf{2 A}$ and $\mathbf{2 B}$ ) showed an ectasia of the trunk of the pulmonary artery, measuring $9.0 \mathrm{~cm}$ in its largest diameter and dilatation of the main pulmonary arteries and cardiomegaly. The three-dimensional reconstruction (Figure 3) allowed a better visualization of aneurysmal dimensions and its relationship to adjacent structures. In addition, the transthoracic echocardiography showed moderate tricuspid insufficiency associated with pulmonary artery hyperten- 
Figure 2A: Axial chest CT with window to mediastinum showing marked dilatation of the pulmonary trunk $(9.0 \mathrm{~cm})$ and the main branches.

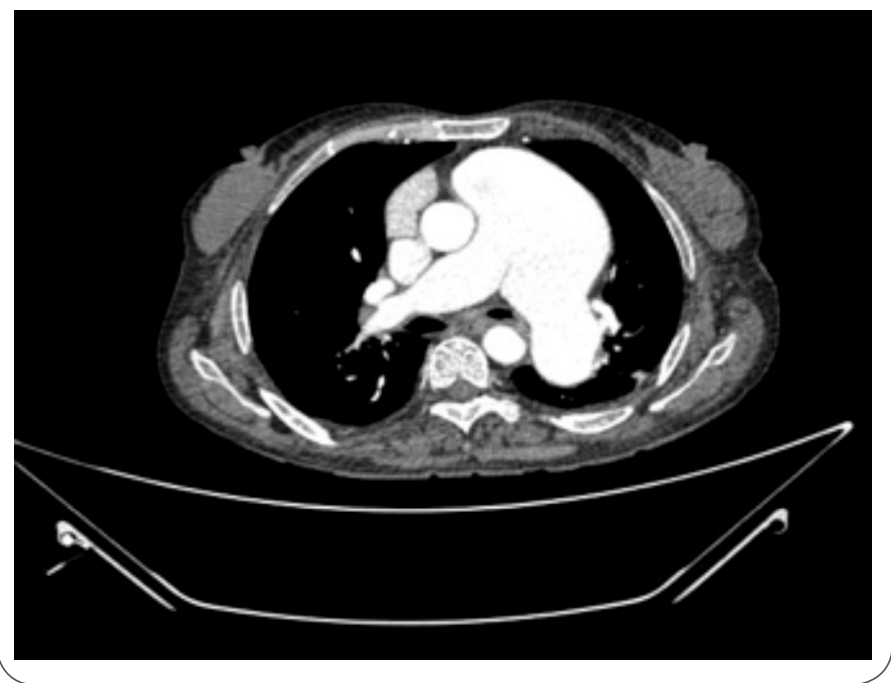

sion $(70 \mathrm{mmHg}$ ) and maintained systolic function. The patient evolved well and because of the lack of symptoms attributed to the aneurysm, the shortage in the literature of recommendations about surgical intervention and the desire of non-intervention by the patient, there was the decision for performance of an expectant approach with outpatient monitoring of the use of nifedipine retard $40 \mathrm{mg} /$ day and periodic computed tomography control.

\section{Discussion}

Pulmonary artery aneurysm is an uncommon clinical entity, diagnosed mainly in autopsy study. Although the majority of patients relate some symptoms such as dyspnea, cough, hemoptysis or palpitation, a part of them evolves asymptomatic. It is noteworthy, therefore, the importance of a thorough physical examination. Currently, because of easier access to imaging methods, some patients with PAA are incidentally diagnosed in radiologic
Figure 2B: Chest CT with coronal plane reconstruction of the aneurysmal dilatation.

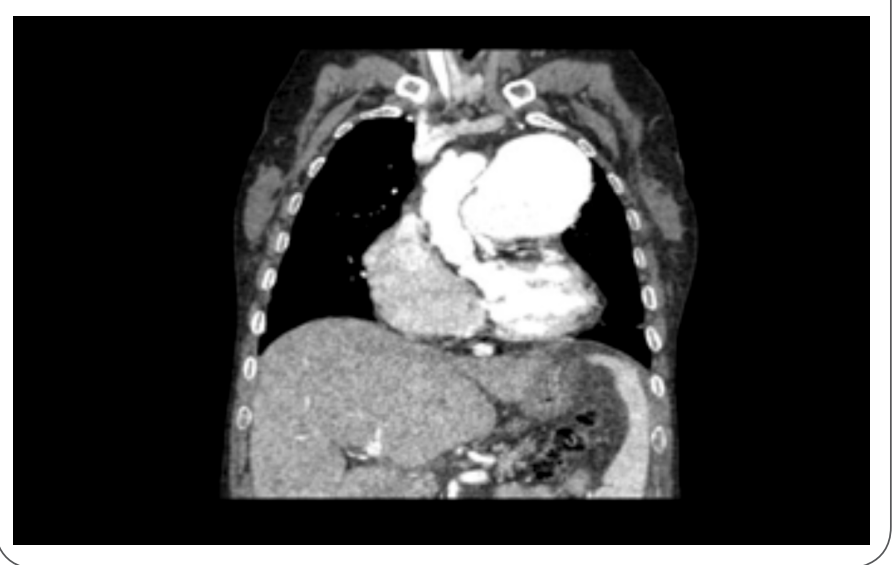

Figure 3: 3D reconstruction showing massive expansion and its relationship to the aortic arch.

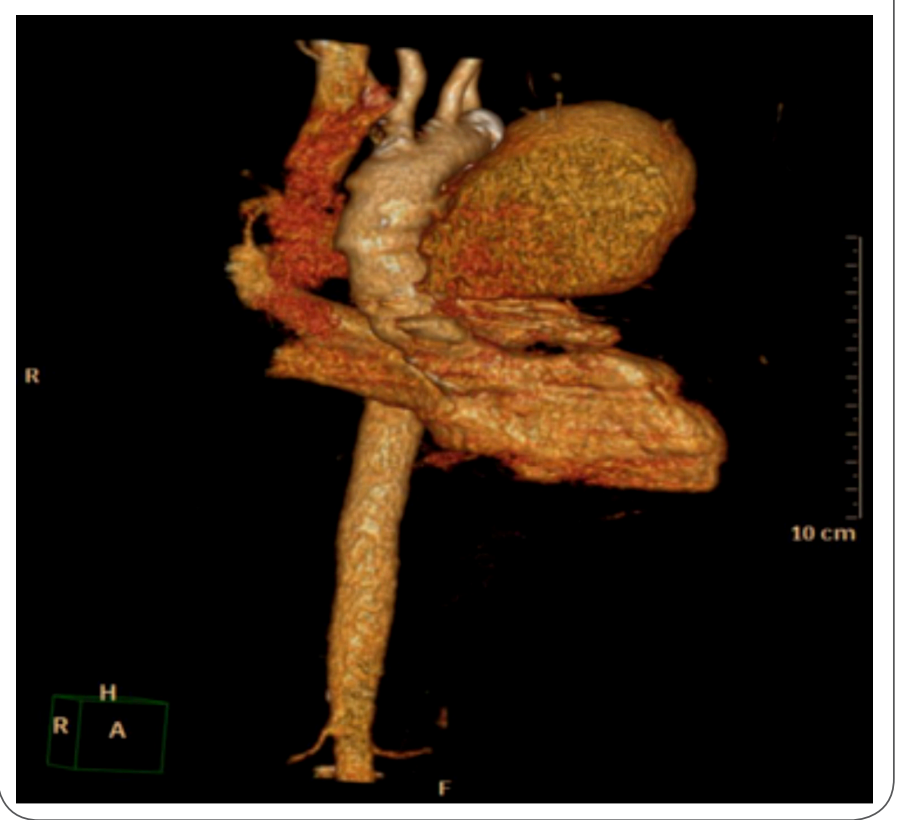

studies, even in the cases of giant aneurysms like the patient described.

According to Nguyen et al., the normal value for the upper limit of the diameter of the main pulmonary artery is of $29 \mathrm{~mm}$ in CT image [4]. The CT scan of our patient showed an aneurysmal dilatation 3 times greater than this limit, with few cases report- 
ed in the literature with similar diameters.

There are still many divergences regarding the treatment of the PAA and there is no specific recommendation. The surgical treatment is usually indicated in the most unstable aneurysms with hemoptysis and in cases in which a fatal outcome because of the increased risk of rupture is foreseeable, such as mycotic aneurysm, the ones associated with Behcet's disease, Hughes-Stovin syndrome, Marfan syndrome and Osler-Weber-Rendu syndrome [1, 12]. Several surgical techniques have been reported as replacement for the Dacron graft, the substitution with the combination of Dacron prosthesis and bioprosthesis, aneurysmorraphy and repair of lung allograft [15].

The greatest concern is over the long term evolution of the cases not treated surgically, because there is little data in the literature. However, there are reports of clinical monitoring that reached 40 years, without complications.

Because of the lack of symptoms attributed to the aneurysm, the shortage of recommendations about surgical intervention in the literature, evidence that the periodic monitoring is safe, absence of an underlying disease and the desire of non-intervention by our patient, there was the decision of performance of an expectant approach with outpatient monitoring and periodic CT control.

\section{Conclusion}

The rarity of the PAA confirms the scarcity of data in the literature and reinforces the importance of the description of case reports, even isolated. As some patients are asymptomatic, a simple physical examination associated with thoracic imaging can identify cases that would be missed in a normal routine. Despite the availability of several corrective surgical techniques there is growing evidence that outpatient treatment is safe. More data are needed in the literature to reinforce the indications of treatment and monitoring of these patients.

\section{References}

1. Smalcelj A, et al. Giant, dissecting, high-pressure pulmonary artery aneurysm: case report of a 1-year natural course. Tex Heart Inst J. 2005;32(4):589-94.

2. Barbour DJ, Roberts WC. Aneurysm of the pulmonary trunk unassociated with intracardiac or great vessel left-to-right shunting. Am J Cardiol. 1987;59(1):192-194.

3. Johnston $\mathrm{KW}$, et al. Suggested standards for reporting on arterial aneurysms. Subcommittee on Reporting Standards for Arterial Aneurysms, Ad Hoc Committee on Reporting Standards, Society for Vascular Surgery and North American Chapter, International Society for Cardiovascular Surgery. J Vasc Surg. 1991;13(3):452-458.

4. Nguyen ET, et al. Pulmonary artery aneurysms and pseudoaneurysms in adults: findings at CT and radiography. American Journal of Roentgenology. 2007; 188(2):126-134.

5. Sakuma $M$, et al. Proximal Pulmonary Artery Aneurysms in Patients with Pulmonary Artery Hypertension: Complicated Cases. Intern Med.2007;46(21):1789-1793.

6. Vanhuyse F, Maureira P, Folliguet T, Villemot JP. Pulmonary Artery Aneurysm : A Case Report and Management of this Uncommon Pathology. Acta Chir Belg. 2014 SepOct;114(5):349-51.

7. Barney D, Brown C, Das D, Kapoor M. Pulmonary artery aneurysm. J Emerg Med. 2015 May;48(5):605-6.

8. Kreibich $M$, et al. Aneurysms of the pulmonary artery. Circulation. 2015 Jan 20;131(3):310-6.

9. Tomas $\mathrm{L}$, et al. Aneurisma idiopático de la artéria pulmonar: Presentación de un caso y revisión de la literatura. An Med Interna 2005,22.329-331.

10. Khalil MZ, Al-Nozha MM, Wani BA. Asymptomatic giant pulmonary artery aneurysm in an elderly male patient. Saudi Med J. 2004;25:802-4

11. Puri $D$, et al. Ruptured pulmonary artery aneurysm: a surgical emergency. Asian Cardiovasc Thorac Ann. 2011 Dec; 19(6):4369.

12. Veldtman GR, Dearani J A, Warnes C A. Low pressure giant pulmonary artery aneurysms in the adult: natural history and management strategies. Heart 2003;89:1067-1070 
13. Gomes $O$, et al. Giant aneurysm of the main pulmonary artery: case report. Rev Port Cardiol. 2008 Nov;27(11):1463-8.

14. Çil BE, et al. Embolization of a Giant Pulmonary Artery Aneurysm from Behçet Disease with Use of Cyanoacrylate and the "Bubble Technique". Journal of Vascular and Interventional Radiology 2005; 16:1545-1549.

15. Kuwaki K, Morishita K, Sato H, Urita R, Abe T. Surgical repair of the pulmonary trunk aneurysm. European Journal of CardioThoracic Surgery. 2000;18(5):535-539.

16. van Rens MTM, Westermann CJJ, Postmus PE, Schramel FM. Untreated idiopathic aneurysm of the pulmonary artery; longterm follow-up. Respiratory Medicine. 2000;94(4):404-405.

\section{Comment on this article:}

\section{(f) $B$ in $8+\boldsymbol{S} P$}

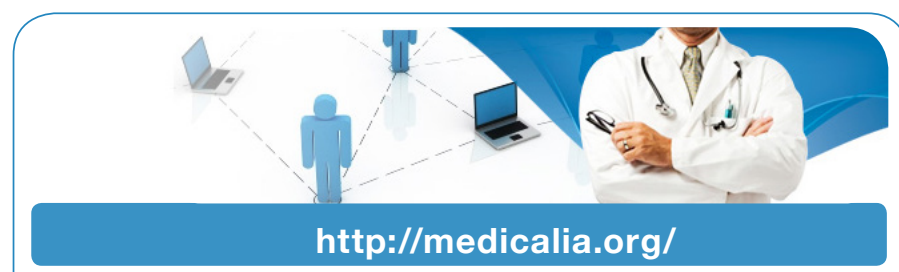

Where Doctors exchange clinical experiences, review their cases and share clinical knowledge. You can also access lots of medical publications for free. Join Now!

\section{Publish with iMedPub}

\section{http://www.imed.pub}

International Archives of Medicine is an open access journal publishing articles encompassing all aspects of medical science and clinical practice. IAM is considered a megajournal with independent sections on all areas of medicine. IAM is a really international journal with authors and board members from all around the world. The journal is widely indexed and classified Q1 in category Medicine. 